\title{
Un territorio propio
}

\author{
Xulio Ricardo Trigo
}

Siempre he pensado que los escritores, los creadores en general, aquéllos que hacen de cualquier tipo de arte su medio de expresión, tienen mucho más que decir de lo que se supone habitualmente. El trabajo creativo pone en juego multitud de resortes que suelen quedar lejos del destinatario, un poco ajeno a asuntos que se consideran casi como los secretos de taller.

Pues bien, cuando Joan M. Ribera me invitó a dar esta charla sobre mi obra, tuve dos sensaciones contrapuestas. Por un lado la "vergüenza", entre comillas, de tocar esos secretos de taller, o el origen, a veces tan evidente para el que escribe, de mis temas literarios. Pero por otra parte me alegré de poner en práctica, de una manera quizá más rigurosa que en otras ocasiones, este proceso de desvelamiento que me ha apasionado en la figura de otros escritores. Vaya por delante, sin embargo, que no es mi intención - lo dejo para críticos i estudiosos- hacer un análisis sesudo de mi obra sino, más bien, profundizar en algunos aspectos - la mayoría vitales - que han configurado mis libros tal cual son. Así intentaré desglosar en unos pocos apartados todo esto.

\section{¿POR QUÉ ESCRIBO?}

Es quizá una de las preguntas más tópicas que se le pueden hacer a un escritor y, al mismo tiempo, también resulta una de las que tienen más difícil respuesta. Cuando pienso en ello veo al hijo único de un pequeño empresario de posguerra que, cosas de entonces, viajaba continuamente con su padre, ajeno a colegios y a institutos hasta bien entrada la juventud. Lo veo pergueñando diarios de viaje llenos de dibujos y de notas sobre las incidencias del 
recorrido, curioseando en las iglesias y pequeños museos de las poblaciones que visitaba. ¿Escribo por eso, por la vida un poco trashumante que llevé hasta los quince años? Quizá no. Pero me quedó de aquella época una curiosidad infinita, un gusto por estar in the road, evidentemente con unas intenciones mucho más ingenuas que las de la generación beat.

De entonces me quedó un gusto por el movimiento, una inquietud viajera y, también, aunque algunos me lo reprochan - ¿cómo es posible en un escritor tan serio como tú?, me dicen - un gusto por los coches y por todo tipo de vehículos a motor que se acerca a la pasión desaforada.

Pero se me ocurre todavía otra respuesta al tópico. Quizá, sólo quizá, escribo porque una vez, hace ya mucho tiempo, mis padres decidieron cambiar de domicilio, trocar las brumas y la humedad de Galicia por el sol y el viento desaforado del Mediterráneo. Gané una patria y una lengua, la catalana, y al mismo tiempo perdí - pienso que en parte, como luego explicaré- otra. ¿Escribo por este destierro, por este alejamiento de las raíces? Todo es posible. Soy gallego, me siento gallego, con frecuencia los temas y los ambientes de mis libros son gallegos, pero, al mismo tiempo, yo no sería nada sin Cataluña, sin la lengua catalana, ni sin las referencias que a lo largo de mi vida allí he ido acumulando. Con frecuencia, con demasiada frecuencia, editores, críticos, no tanto lectores, que parecen ser mucho más abiertos y universales que los anteriores, se quejan de la galleguidad que impregna muchos de mis libros. Yo siempre respondo si tienen el mismo problema a la hora de no saber absolutamente nada del Rouen de Flaubert, del Montevideo de Onetti, del París de Cortázar. Pocas veces encuentro razones, argumentos para esta falta de sensibilidad universal que nos hace limitarnos.

Pero sigamos la pregunta: ¿Quizá escribo por una sensación de extrañamiento de aquella tierra que perdí? A veces lo creo, y también, por encima de todo, me gusta recordar las teorías que al respecto tiene un escritor admirable por su espíritu crítico, por la ambición de sus primeras novelas, aunque su trayectoria cívica y el lugar donde han desembocado sus ficciones no me merezcan el mismo respeto. Me refiero a Vargas Llosa y a esa teoría, que tanto nos ha influido a muchos, de deicidio. Vargas Llosa ve a los escritores como una especie de envidiosos del poder divino, como seres que quisieran crear mundos de ficción que llegasen a tener la misma fuerza que el mundo real. Creo que comparto esta ambición, esta manía, esta locura. Yo quiero crear mundos paralelos y nunca me ha interesado especialmente reflejar la realidad tal cual es. Me apasiona sin embargo la apariencia de realidad que puede trasmitir una obra de arte, una novela, una escultura; siempre bajo una máxima indispensable: La realidad, ya lo decía Borges, es todo aquello que vivimos. Y vivimos los sueños, lo cotidiano, la desesperanza, el cine, las novelas, la magia, lo horrible... Todo ello conforma una realidad múltiple, la que genera los materiales para construir nuestras apariencias de realidad, aquellos que convierten en una empresa fascinante, a menudo inaprensible, la creación literaria, quizá una buena razón para explicar nuestro vicio. 


\section{UN TERRITORIO PARA LA FICCIÓN}

Posiblemente el problema más coercitivo al que me he tenido que enfrentar para escribir ficciones es dilucidar cual era mi territorio, donde tenían que pasar mis novelas, mis historias, qué referentes convenían, o se imponían, en mis poemas. Y nos movemos, una vez más en el territorio de los tópicos. Sí, tal como decía Baudelaire, mi patria es mi infancia. Y es que a finales del siglo $\mathrm{XX}$ hay una serie de lugares comunes que responden a la llamada de cualquier creador. Dentro de esta circunstancia tengo que decir que también cada uno tiene su propia historia, su propia bifurcación que al mismo tiempo lo aleja y lo acerca al tópico.

Si mi mundo de referencia era Galicia, me tenía que enfrentar a ese recuerdo, a sus sensaciones, para escribir aquello que quería escribir - y es que otra cosa es el oficio, aquello que con el tiempo te hace capaz de escribir sobre casi cualquier cosa-. Pero yo me he propuesto hablar aquí de los verdaderos motivos, de los impulsos que consiguen esa extraña alianza entre el ser humano y la creación. Pienso que la respuesta a estas dudas - se ha de pensar que yo fui arrancado muy pronto del país, Galicia, que me sirve de referencia creativa- la respuesta entonces, quizá, sólo quizá, la debí encontrar en mis lecturas.

$Y$ muy pronto las lecturas me informaron de que los escritores crean mundos de ficción para su propio oficio y, con menos frecuencia, beneficio. El caso más evidente a todos puede ser el del Macondo de García Márquez, pero también la Yoknapatawpha de Faulkner, la Mágina de Muñoz Molina, la Región de Benet... La lista no es interminable pero podría ser larga.

¿Qué encontré en este territorio creado por mi, el que en alguno de mis libros se denomina Ligàcia? En primer lugar: libertad. Esa Ligàcia ha sido capaz de ayudarme a esconder una evidencia: en mi mundo literario el olvido y la invención, al unísono, se ocupan de subsanar los huecos. Es evidente que la distancia y el tiempo han contribuido a crear Ligàcia y que, esta, a pesar de ser reconocible, es una Galicia de cuento, una Galicia transcendida en otra realidad que yo llamo Ligàcia después de hacer un simple juego de cambio silábico.

Quiero decir que, gracias a este truco, nada excesivamente original por otra parte, queda a salvo mi integridad y la del país que he tomado como referencia. Si el territorio es mío puedo equivocarme o, tal y como postulaba Vargas Llosa, cambiar el orden de las cosas. No es extraño, pues, que una de mis novelas lleve por título Fado o l'ordre de les coses.

\section{LA DIVERSIDAD DE LA FICCIÓN}

Otro aspecto que quiero tratar es lo que llamo la diversidad de la ficción. Podría parecer, a aquél o aquélla que me esté escuchando, que mi mundo lite- 
rario es un universo rígido, casi monolítico, y nada queda más lejos de la realidad. Todavía, a pesar de haber reflexionado muchas veces sobre el tema, no he decidido si mi pluralidad literaria es un aspecto que me haga feliz o, incluso, si no me perjudica debido a la dispersión que por momentos supone.

Para mí, la creación literaria no se concentra tanto en las palabras que designan el género. Se dice: “iEs un novelista! Es un poeta! ¡Escribe cuentos!” Y, muy a menudo, da la impresión que sólo es eso, que sólo puede ser eso. Mi idea de la literatura es, inevitablemente, plural y se concentra en la palabra escritura. Si me puedo permitir una pedantería, dejadme que me autodenomine un escritor.

Siempre he pensado que son los temas, o quizá mejor las circunstancias de la escritura, las que dictan el género, las que, de alguna manera, lo imponen. Llevado por esta idea, he escrito poesía, cuento, novela, ensayo, aquello que llamamos literatura del yo, es decir: diarios, libros de viajes, etc. Y lo he hecho consciente de la dispersión que a veces ha supuesto. Ahora bien, si me obligaseis a escoger un género, si tuviera que decidir cual es aquel del que me gustaría que quedase alguna cosa, este seria sin duda la novela, y ella será, sobre todo, el motivo central de esta conferencia.

Antes de seguir adelante, debo decir una cosa: no toda mi obra narrativa tiene como escenario ese territorio pretenciosamente mítico de Ligàcia. Con ello pretendo quizá oxigenar al lector y a mí mismo, aunque por momentos signifique renunciar a una baza que, según creo, otorga a mi narrativa un punto de vista más profundo.

Yo no sé si de pequeños habéis jugado alguna vez a tener un Estado, a ser vosotros mismos un Estado - con sus leyes, su constitución, sus guardianes. Este juego, a veces terrible, del territorio propio, es como la posesión de un inmenso jardín que debemos cuidar hasta el último extremo. El esfuerzo para dar coherencia a ese mundo, que vive incluso cuando tú has decidido poner tierra por medio, es brutal, hasta el punto que una de mis principales aficiones, no sé si obligado por las circunstancias, es la confección de un fichero, lo que llamo la Enciclopedia Ligaciana, donde voy incluyendo las partes de ese mundo que por momentos amenaza con tragárseme. Os confieso que, en alguno de mis delirios ligacianos, he estado muy cerca de decidir la publicación futura, naturalmente- de esta enciclopedia tan inútil.

\section{CLASICISMO Y NARRATIVIDAD}

Pero como ni: quiero extenderme demasiado, no fuera que odiaseis mi obra incluso antes de conocerla, pasaré a hablar de algunas cosas que pienso pueden ayudar a situar mi obra hasta el momento. Me considero un escritor clásico, es decir, un narrador o, si queréis, un amante de la historias como centro 
de la actividad narrativa. Esto no quiere decir que no utilice los indudables avances que, bien sea a través de las vanguardias de este siglo, bien por el espíritu, menos realista de lo que se ha querido ver, de la novela del XIX, o a través de la recuperación, en la relectura efectuada sobre todo por los escritores sudamericanos, de la literatura medieval, han comportado a este oficio en los últimos tiempos. Aquel novelista, aquel escritor que no las tenga en cuenta será un ser inevitablemente anticuado, pero asimismo, aquél que sólo quiera seguir alguno de estos movimientos de manera excluyente, también errará el tiro.

Pienso que la historia nos ha colocado en una circunstancia inmejorable $y$ que la labor, inmensa, sin duda, del escritor a finales del siglo XX, es intentar la conjunción de las tradiciones acumuladas, también la surrealista o las vanguardias, para crear lo que debería ser la narrativa del siglo que se acerca. Quizá es muy ambicioso, quizá es irrealizable, una utopía, pero cuando se habla de estas cosas creo que no está de más considerar cuáles pueden ser los ideales, el mejor panorama posible.

\section{LA SENSUALIDAD. LA INTRIGA}

Ya he explicado que, sin rechazar las técnicas y los descubrimientos de este siglo, mi literatura intenta, por encima de todo, contar historias. Y cuando te cuentan una historia existen dos elementos fundamentales. Un de ellos es la sensualidad. Y no sé si necesita explicación. Sé que aquella obra de ficción narrativa que carece de un tratamiento importante de la sensualidad entre los personajes deja, en buena medida, de interesarme. Es, por poner un símil, como aquellas novelas con náufrago que nunca trataban de las funciones esenciales del ser humano. Su pretendido realismo se tornaba pastiche edulcorado y limpio, y la vida es una combinación de suciedad y nitidez, de horror y maravilla. La sensualidad, que incluye las relaciones entre las personas, muy a menudo, por no decir siempre, condicionadas por el influjo del sexo y sus contornos, es fundamental para hacer creíble un asunto literario. Naturalmente, la sensualidad puede estar implícita, puede ser una fantasía que el texto provoca en el lector. Flaubert, D. H. Lawrence, escritores con una gran capacidad para trasmitir estas sensaciones en sus novelas, obvian muy a menudo lo explícito sin que el texto se resienta. Sólo cabe recordar el paseo en calesa que dan los protagonistas de Madame Bovary, un prodigio de insinuación y de sutileza que, no obstante, deja las cosas muy claras al lector.

Otro aspecto que quería destacar es la intriga. Quizá uno de los elementos más importantes del género novelístico es la intriga, es decir, la manera como se nos presentan los acontecimientos y cómo repercuten en el lector. No hablo, al menos no exclusivamente, de intriga de corte policial, sino de aquel elemento que ayuda a mantener la atención del lector. La novela ideal quizá sería aquella que, en cada párrafo, contribuyera a la perplejidad y al interés crecien- 
te del que la lee. En esto es cierto que la novela de misterio, la ficción policial sobre todo, ha contribuido muchísimo a ensanchar las posibilidades del género. Además soy de los que piensan que la novela policial puede ayudar como pocas a la radiografía de una sociedad. No os extrañe pues que yo, en mi delirio de creación de un mundo, contemple este mal llamado subgénero como una posibilidad muy apetecible, tal y como demuestra la serie del detectiu privat Xurxo Fondo, del qual ya he publicado una primera entrega, La mort salobre. Así mismo me he servido de la intriga criminal en una novela sin intención de género, como La desaparició d'Evelyn.

En esto de escribir novelas cada escritor propone sus propias soluciones. Sin embargo, uno de los recursos que más me han ayudado a la hora de escribir ficciones ha sido lo que me agrada denominar el cuaderno de campo. Cuadernos, libretas de notas, me han sido siempre muy útiles, igual que las fotografías, los mapas cartográficos y otros elementos, como el trabajo in situ, que colaboran en esa creación de un mundo paralelo pero autónomo que llevamos a cabo los escritores. Mis cuadernos de trabajo, aquellos que con un símil naturalista me gusta llamar cuadernos de campo, son mis notas a pie de mundo, y me ayudan a conformar los lugares y ciudades donde ocurren mis ficciones, más que con una voluntad realista o testimonial, con una intención plástica y estética, a veces un tanto impresionista. Pocas cosas hay tan útiles para un escritor como un cuaderno y, a veces, éstos se publican. Uno de mis libros, L'extensió del temps, es producto de dos viajes a lugares muy presentes en mi obra - Santiago y el Pirineo Catalán- y se trata de una selección de sus respectivos cuadernos de campo. Es un diario de impresiones, de lecturas, de paisajes y también un libro de ruta. Tal como reconoció el jurado que le otorgó el premio Enric Valor de novela, se trata de la novela interior de un escritor. Soy un enamorado de los libros personales, y siempre he pensado que necesitan elementos que nos ayuden a romper la inercia de leer una nota y dejarlo en la estantería sin preocuparnos del conjunto. L'extensió del temps es mi pequeña contribución a esa causa.

Pero estas consideraciones no estarían completas sin confirmar un aspecto que quizá haya quedado implícito pero que no he formulado del todo. Y es que el placer de la historia, de la narrativa pura, no sería nada ni puede olvidar que está a merced del lenguaje, de un código de signos que aspira a una voluntad estética cuando esto se llama literatura.

Aquí termino. Pienso que el principal objetivo de un escritor como yo es escribir un buen libro, pero eso, desgraciada e ingratamente, sólo el lector puede decirlo y, con sinceridad, si lo dijerais, siempre desconfiaría de haberlo conseguido. No es tarea fácil, pues, pero a veces, sólo a veces, se siente algo cercano a la felicidad o al poder supremo. 